\title{
HOLDE'S TEST AND THE DETECTION OF PARAFFIN WAX, ETC., IN LARD AND OTHER FATS.
}

\author{
By H. DUNLOP. \\ (Read at the Meeting, November 3, 1909.)
}

THE excellent test due to Holde for the detection of mineral oil in fatty oils can be applied with advantage to the testing of lard for paraffin wax, and is, in the author's opinion, more delicate and economical both in time and material than that proposed by Shrewsbury (ANALYST, 1909, 348).

Although Holde's test is well known, a short description may not be out of place. From 0.3 to $0.35 \mathrm{grm}$. (10 drops) of the melted fat is saponified in a testtube with 5 c.c. of approximately $\frac{\mathrm{N}}{2}$ alcoholic potash, and to the clear hot soap solution water is added in successive quantities of about 1 c.c., the solution being carefully observed after each addition of water. While pure lard gives a clear solution of soap after dilution with 5 c.c. of water, the presence of even 0.5 per cent. of paraffin wax is indicated by the formation of a turbidity, the "silky" appearance of which is characteristic of paraffin wax.

A series of tests on prepared mixtures proved that it is possible by this method to detect as little as 0.3 per cent. of paraffin wax in lard or margarine fat.

Although several cases of adulteration of lard with paraffin wax have been recorded, its employment in the manufacture of margarine appears to have escaped notice. In 1907 the author had the opportunity of examining a sample of margarine containing 7 per cent. of paraffin wax in the sample, and for the fat of which the following figures were obtained:

Saponification value, 179.5 ; soluble volatile acids, 2.5 ; insoluble volatile acids, 0.5 ; Zeiss refractometer (at $40^{\circ} \mathrm{C}$.), 49.8 ; solidifying point, $39^{\circ} \mathrm{C}$. It is scarcely necessary to state that the presence of paraffin wax could be easily detected in the mouth.

Holde's test also serves as a rapid sorting-test in the examination of tallow, which article is now frequently adulterated with "fish-oil stearine" and paraffin wax, samples recently examined containing from 1 to over 20 per cent. of the latter adulterant.

Since writing the above, the author has examined two samples of margarine, the fat of which contained 19 per cent. of "soft paraffin" (vaseline) and 0.4 per cent. of paraffin wax respectively.

\section{Discussion.}

The Chairman ( $\mathrm{Mr}$. Cribb) remarked that the advantage of this method seemed to be its rapidity and the small quantity of material required. It was, however, obviously merely a process for estimating unsaponifiable matter, and would not distinguish between paraffin and any other unsaponifiable substance.

Mr. E. R. BoLton said that he had hoped that the author was going to describe 
some test capable of detecting the infinitesimal quantities of paraffin which might be added to lard, with the object of interfering with the phytosterol acetate test for vegetable oil.

$$
* * * *
$$

